\title{
A Política Externa Brasileira em relação ao Fundo Monetário Internacional durante o Governo Lula
}

The Brazilian Foreign Policy concerning the International Monetary Fund during the Lula Administration

JOÃO MARTINS TUDE* CARLOS SANCHEZ MILANI**

Rev. Bras. Polít. Int. 56 (1): 85-103 [2013]

\section{Introdução}

O Brasil tem mantido relações formais com o Fundo Monetário Internacional (FMI) desde as conferências que o conceberam. Essas relaçōes vêm variando desde então por conta dos diferentes contextos políticos e econômicos, no âmbito internacional e doméstico, assim como pela natureza das relaçôes Brasil-EUA, entre alinhamento, aliança, autonomia e distância crítica (Hirst 2009). Durante o governo Fernando Henrique Cardoso (FHC), um novo ciclo no relacionamento entre o FMI e o governo brasileiro se iniciou: a relação entre a administração FHC e o FMI se deu de maneira cooperativa, não havendo obstáculo político para que o governo brasileiro solicitasse apoio junto ao Fundo quando necessitou.

No governo FHC se buscou "imprimir coerência à ação externa", consolidando a lógica da autonomia pela integração (Fonseca Júnior 1998) pela qual o Brasil buscou, internacionalmente, uma maior integração financeira e comercial e "completa adesão aos regimes internacionais, possibilitando a convergência da política externa brasileira com tendências mundiais, evitando, assim, o seu isolamento diante do mainstream internacional" (Vigevani, Oliveira, e Cintra 2003, 36). Acreditava-se que, em um ambiente de abertura ao capital internacional, o País seria beneficiado pelos investimentos diretos, já que a concorrência forçaria a indústria nacional a se modernizar, ao passo que o fechamento do mercado nacional, por sua vez, só aprofundaria a "defasagem em relação aos países ricos e mesmo aos outros países subdesenvolvidos" (ibidem, 33). Na perspectiva crítica de Cervo e Amado (2010), essa nova lógica da política externa se vincula

\footnotetext{
* João Martins Tude é professor assistente da Universidade Federal de Alagoas (Ufal) (joaomtude@yahoo.com.br)

** Carlos R. S. Milani é professor adjunto do Instituto de Estudos Sociais da Universidade Federal do Rio de Janeiro (IESP-UERJ)(crsmilani@iesp.uerj.br)
} 
à emergência do paradigma do Estado Normal nas estratégias internacionais do Brasil, fundamentado nos ideários neoliberais do Consenso de Washington e na expectativa de que a adesão brasileira aos regimes internacionais produziria distribuição mais favorável do poder político nas relaçōes internacionais. Essa conformação da política internacional e econômica do governo FHC contribuiu substancialmente para um padrão de bom relacionamento com o FMI.

Em 2003, a nova estabilidade adquirida no ano anterior foi interrompida com o recrudescimento da crise no Cone Sul. Desse modo, a inexistência de qualquer acordo entre a Argentina e o FMI, bem como a drenagem do sistema bancário uruguaio com o fechamento de agências e o bloqueio de depósitos, fez com que o Brasil se deparasse com nova crise financeira, além de um declínio abrupto e significativo da paridade do real em relação ao dólar. Um novo acordo com o Fundo se fez, então, necessário. Contudo, o FMI hesitava em realizar esse novo acordo frente à grande possibilidade de Lula ser eleito presidente da República. O Partido dos Trabalhadores (PT) sustentava historicamente uma série de críticas ao FMI, considerado pelo partido um símbolo de dominação política e submissão internacional. Entretanto, foi possível a obtenção da renovação do acordo com o FMI no segundo semestre de 2002, mas somente após a publicação da "Carta aos Brasileiros" pelo então candidato Lula, na qual ele afirmava que, se eleito fosse, respeitaria os contratos assumidos. Também foi fundamental para essa renovação do acordo com o Fundo a obtenção pelo governo FHC do apoio formal de todos os candidatos à presidência do País, após reunião realizada com cada um deles em Brasília.

Como condicionalidade inserida no referido empréstimo, o Brasil firmou o compromisso de manter o nível do superávit primário em 3,75\% do PIB em 2003 e sua previsível recondução nas diretrizes orçamentárias de 2004 e 2005. Além disso, o País deveria devolver cerca de US\$ 10 bilhôes desse empréstimo, em junho de 2003. Meses após o novo acordo com o FMI, Luís Inácio Lula da Silva foi eleito presidente do Brasil. Apesar do apoio formal do novo presidente a essa renovação de acordo garantido durante a campanha eleitoral, havia ainda expectativas e dúvidas quanto à forma como ele e seu governo se relacionariam com o Fundo. Passados oito anos de governo Lula, vêm à tona as questôes que orientaram a pesquisa cujos resultados principais sintetizamos neste artigo: como se configurou a política externa do governo Lula em relação ao FMI? Como o governo Lula se posicionou no que tange às reformas dessa agência financeira internacional?

Para realizar a presente investigação foram utilizados os métodos de pesquisa bibliográfica e documental. A pesquisa bibliográfica percorreu minuciosamente livros, artigos e matérias jornalísticas que abordavam os temas relativos ao FMI, à política externa brasileira e ao processo de reforma da governança financeira internacional. Já a pesquisa documental ocorreu a partir da análise de 3.148 discursos oficiais, entrevistas, apresentaçôes e notas da Presidência da República, do Ministério da Fazenda e do Ministério das Relações Exteriores, 
durante o governo Lula. Para analisar esses documentos foi utilizado o método de Análise de Conteúdo, com abordagem quantitativa ${ }^{1}$ e qualitativa, seguindo modelo proposto por Bardin (1977).

\section{Os primeiros anos do governo: estabilização macroeconômica e continuidade política}

O aumento da frequência absoluta e relativa do termo "FMI" nos discursos do presidente Lula e de seu ministro das Relaçôes Exteriores, Celso Amorim, como se pode verificar nas Tabelas 1 e 2 a seguir, indica, de maneira preliminar, a importância crescente que tal instituição teve na agenda política do governo entre 2003 e 2010. De fato, Lula foi eleito presidente em um momento de elevada instabilidade econômica. Durante o período eleitoral de 2002, o real fora altamente desvalorizado (sua cotação frente ao dólar chegou aos $\mathrm{R} \$ 4,00$ ) e o risco-país superou os 2.000 pontos, ocasionando forte aumento dos juros acessíveis ao Brasil no mercado financeiro internacional. Nessa época, o Brasil respondia por mais de $20 \%$ do total dos empréstimos do FMI, sendo o segundo maior devedor do Fundo, logo depois da Turquia.

Tabela 1. Discursos proferidos por Lula.

\begin{tabular}{|l|r|r|r|r|r|r|r|r|r|}
\hline & $\mathbf{2 0 0 3}$ & $\mathbf{2 0 0 4}$ & $\mathbf{2 0 0 5}$ & $\mathbf{2 0 0 6}$ & $\mathbf{2 0 0 7}$ & $\mathbf{2 0 0 8}$ & $\mathbf{2 0 0 9}$ & $\mathbf{2 0 1 0}$ & Total \\
\hline Discursos proferidos (total/ano) & 288 & 320 & 284 & 257 & 341 & 319 & 312 & 366 & 2.487 \\
\hline Discursos que mencionam o FMI & 5 & 7 & 20 & 28 & 39 & 47 & 53 & 67 & 266 \\
\hline $\begin{array}{l}\text { Porcentagem de discursos que } \\
\text { mencionam o FMI (\%) }\end{array}$ & 1,7 & 2,2 & 7,0 & 10,9 & 11,4 & 14,7 & 17 & 18,0 & 10,7 \\
\hline
\end{tabular}

Fonte: elaboração própria.

Tabela 2. Discursos proferidos por Celso Amorim.

\begin{tabular}{l|r|r|r|r|r|r|r|r|r}
\hline & $\mathbf{2 0 0 3}$ & $\mathbf{2 0 0 4}$ & $\mathbf{2 0 0 5}$ & $\mathbf{2 0 0 6}$ & $\mathbf{2 0 0 7}$ & $\mathbf{2 0 0 8}$ & $\mathbf{2 0 0 9}$ & $\mathbf{2 0 1 0}$ & Total \\
\hline Discursos proferidos (total/ano) & 54 & 69 & 64 & 84 & 45 & 31 & 28 & 40 & 415 \\
\hline Discursos que mencionam o FMI & 1 & 2 & 3 & 3 & 1 & 6 & 5 & 6 & 27 \\
\hline $\begin{array}{l}\text { Porcentagem de discursos que } \\
\text { mencionam o FMI (\%) }\end{array}$ & 1,9 & 2,9 & 4,7 & 3,6 & 2,2 & 19,4 & 17,9 & 15 & 6,5 \\
\hline
\end{tabular}

Fonte: elaboração própria.

1 Deve-se ressaltar que os discursos do presidente Lula e do ministro Celso Amorim são disponibilizados pelo website do governo federal em sua íntegra. Já no caso dos ministros da Fazenda, não há regularidade na publicação das suas falas e muitos dos arquivos só continham as apresentações utilizadas, mas não as transcriçōes completas de suas falas. Assim, a análise do material de Lula e Amorim pôde ser realizada tanto por procedimentos qualitativos quanto quantitativos, ao passo que os discursos dos dois ministros da Fazenda, pela falta de regularidade, só puderam ser analisados de maneira qualitativa. 
Ao assumir o governo em 2003, diferentemente do "terrorismo monetário" previsto por especuladores, Lula estruturou sua política econômica com base no preceito da continuidade em relação ao governo FHC. Para minimizar as preocupaçóes alardeadas por agências internacionais de rating, Lula convidou Henrique Meirelles, figura conhecida internacionalmente por ter sido ex-presidente do Bank of Boston, para ocupar o posto de presidente do Banco Central do Brasil. Importante notar que Meirelles fora o candidato (pelo PSDB) mais votado para deputado federal de Goiás, porém não chegou a ocupar a sua cadeira na Câmara dos Deputados por haver aceito o convite. Além disso, "o governo brasileiro firmou unilateralmente o compromisso com o FMI de aumentar o superávit primário para $4,25 \%$ do PIB. Esse aumento significou um corte de R $\$ 14$ bilhôes do orçamento" (Gonçalves 2005, 174).

Para assumir o Ministério da Fazenda, Lula escalou Antônio Palocci, segundo o qual todos os acordos com o FMI deveriam ser cumpridos, sem alteração da política econômica brasileira, o que não deixou de provocar reaçôes calorosas da esquerda nacional e sul-americana. Em 2003, o presidente Lula fez breves mençóes ao FMI em 5 dos seus 288 discursos proferidos, e no primeiro deles, em maio de 2003, o presidente parece justificar as medidas econômicas tomadas: "o terrorismo que venderam sobre nós desapareceu com algumas medidas sensatas que nós tomamos. Porque falar, às vezes, é mais fácil do que fazer. Em economia, a gente, muitas vezes, faz e não fala, porque, se falar, não faz" (Lula 2003a).

Assim, no início de 2003, as relações do novo governo com o FMI foram baseadas no respeito aos acordos estabelecidos e na política de não confrontação. Entretanto, já em setembro de 2003 pôde-se perceber o desejo do presidente Lula em diminuir as relações de proximidade com o Fundo. Nesse mês, o presidente discursou por duas vezes sobre a possibilidade de não renovar o acordo de 2002 com o FMI, o qual venceria em dezembro de 2003, mas ressaltou que isso se daria sem fazer "embate ideológico", mas a partir de "uma decisão política, com visão na economia do País" (Lula 2003b, 2003c). Como sublinha Almeida $(2004,170)$ "o FMI constituía, como é sabido, um dos principais objetos da demonologia econômica do PT, durante toda a sua história, opondo-se o partido e o seu candidato a qualquer acordo que limitasse a soberania brasileira". Pode-se deduzir a situação pouco confortável para o presidente Lula em manter acordos com o FMI pela frequência que ele relembra, em seus discursos, seu passado de protestos contra o Fundo, como o proferido em 25 de setembro de 2003: "É importante lembrar que durante parte da nossa vida, e da minha, sobretudo, nós passamos gritando: 'Fora FMI'” (Lula 2003c). A seguir, para ilustrar esse argumento, apresenta-se na Figura 1 a frequência absoluta do tema "Relembrar passado de protestos contra o FMI” nos discursos de Lula durante o seu governo. 


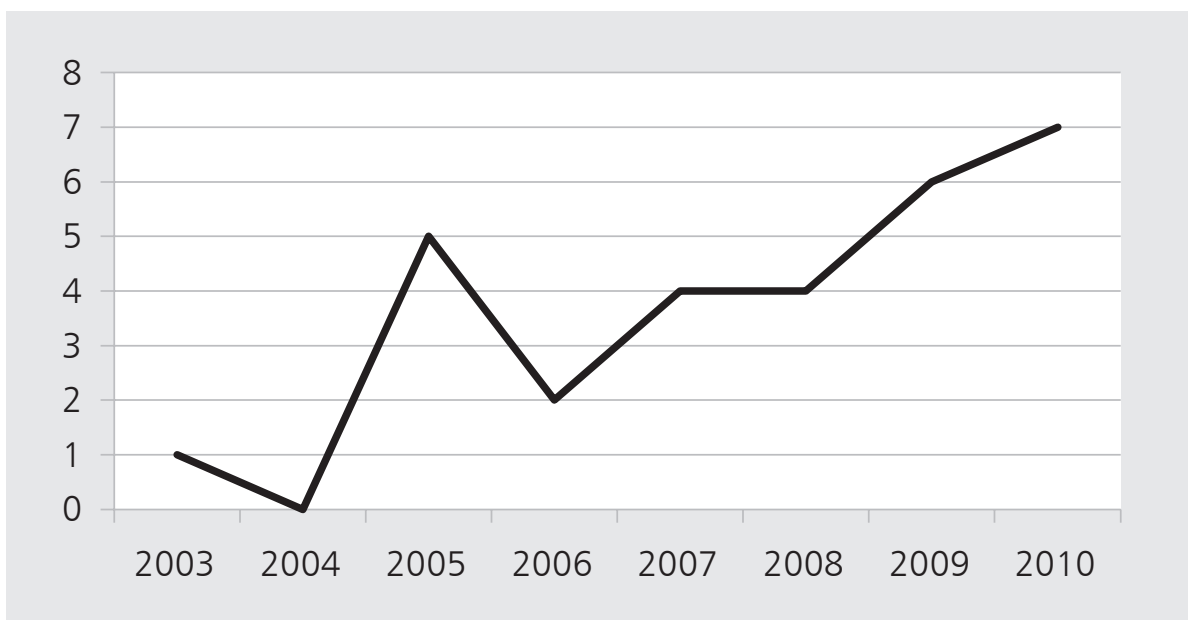

Figura 1. Número de discursos de Lula relembrando a sua militância contra o FMI. Fonte: elaboração própria.

Vale ressaltar a coincidência, ilustrada na Figura 1, entre o momento de campanha eleitoral de 2006 e a redução das menções à militância de Lula contra o FMI, de um lado, e o aumento dessas mençōes quando o Governo Lula afirma sua política externa mais soberana e autônoma, por outro lado. Esse segundo momento corresponde a uma nova fase de crescimento econômico sustentado, de reconhecimento internacional do Brasil e a um período de crises globais (entre 2007 e 2010), em que o papel do FMI foi publicamente debatido e suas falhas na regulação financeira foram apontadas por gestores, políticos e analistas.

Entretanto, o governo, sob influência do pragmatismo de Antônio Palocci, então ministro da Fazenda, decidiu, em 2004, prorrogar por mais 15 meses o acordo com o Fundo, apesar de não ter havido necessidade de sacar mais recursos disponíveis nesse período. Em março desse ano, Lula entrou em contato com diversos chefes de Estado dos países desenvolvidos a fim de solicitar apoio a uma proposta brasileira de revisão dos acordos firmados com o FMI. Tal proposta preconizava que os investimentos em infraestrutura não fossem contabilizados como despesa pública, flexibilizando, assim, a meta de superávit primário acertada com o Fundo. A defesa de tal proposta é o único tema em todos os sete discursos proferidos por Lula que mencionam o FMI ao longo de 2004. De acordo com Gonçalves (2005), esse movimento governamental de defesa que investimentos em infraestrutura não fossem contabilizados como despesa pública causou grande estranheza, já que o valor programado em investimentos para 2004 era de R \$ 12 bilhóes, valor menor do que o governo teve que economizar no ano anterior devido ao seu ato de aumento voluntário do superávit primário. Reinaldo Gonçalves $(2005,176)$ avalia que: 
A iniciativa do presidente brasileiro em 2003-2004 mostra que o governo, além de replicar a política de ajuste macroeconômico do governo anterior, não tem uma estratégia sólida e eficiente de atuação junto ao FMI. Em lugar de o país ter uma posição firme quanto à reforma das instituiçóes de Bretton Woods (FMI e Banco Mundial), o governo parece se perder em inócuas jogadas de diplomacia presidencial, ou seja, marketing pessoal. Nesse sentido, a percepção é de que a política econômica externa do país é determinada, prioritariamente, por fatores subjetivos que têm a ver com as idiossincrasias do tomador de decisão (Gonçalves 20005, 176).

Em abril de 2004, o governo brasileiro foi "autorizado pelo FMI a apresentar projetos-piloto de investimentos em infraestrutura, com o benefício de exclusão dos desembolsos do cálculo do superávit financeiro”, desde que comprovasse que tais investimentos teriam retorno financeiro (Folha de São Paulo 2004, B1). Em fevereiro do ano seguinte, o FMI aprovou os projetos-piloto brasileiros, liberando em torno de US\$ 1 bilhão anual, para os três anos seguintes, em "investimentos públicos em infraestrutura e outras áreas com retorno potencialmente alto em termos macroeconômicos e fiscais" (Valor Econômico 2005, C1). Entretanto, isso não significou que o FMI houvesse alterado o seu método de calcular o superávit dos países, ou seja, investimentos em infraestrutura ainda seriam considerados despesas em outros casos.

O primeiro discurso do presidente Lula que cita o FMI, no ano de 2005, ocorreu em 22 de fevereiro e visou a comunicar que o governo brasileiro não faria a renovação dos acordos com o Fundo em março desse ano. Para alguns especialistas, a não renovação do acordo fazia sentido, na medida em que o País já não se encontrava mais em crise, estava obtendo superávits nas transações correntes e havia reduzido de maneira consistente sua vulnerabilidade externa; para outros, a vulnerabilidade externa ainda era elevada, razão pela qual qualificavam como erro o fato de o governo não renovar o acordo. Entretanto, para além dos aspectos relativos à racionalidade econômica, Gonçalves defende que o determinante de tal ato teria sido:

[...] a conjuntura política em geral e os conflitos de interesses em particular. Ou seja, o ciclo político brasileiro passou a ser influenciado pelas eleições presidenciais de 2006. Tendo em vista o estigma do FMI, o grupo dirigente (governo federal) não teria interesse de carregar até as eleições presidenciais de 2006 o ônus de ter mantido um acordo com o FMI durante todo um mandato (Gonçalves 2005, 178-179).

Pode-se perceber a relevância desse fato para o governo federal pela sua decisão em comunicá-lo em rede nacional de televisão e rádio. Tal pronunciamento foi feito pelo ministro Palocci. Se levarmos em consideração os mandatos de Palocci e Mantega, esse meio de comunicação foi usado tão somente em três ocasiōes ao longo dos oito anos. 
Outro tema inserido na agenda política do governo com o FMI desde o final de 2004, que ganhou mais importância em 2005, foi a defesa de novos mecanismos de financiamento do desenvolvimento e combate contra a fome e a pobreza. Essa política foi comunicada a seguir pelo governo brasileiro a diferentes âmbitos e instituiçôes internacionais, passando a fazer parte das agendas da política externa brasileira. Todas as três declaraçôes do ministro Amorim que se referiram ao FMI ao longo do ano de 2005 abordaram esses temas, assim como 4 dos 20 discursos de Lula sobre o Fundo, nesse mesmo ano.

No final de 2005, outra decisão foi tomada pelo governo Lula no sentido de maior desvinculação em relação ao FMI: foram pagos de maneira antecipada aproximadamente 10,8 bilhóes de Direitos Especiais de Saque (DES) - cerca de US\$ 15 bilhōes - referentes aos empréstimos tomados junto ao Fundo. Tal ato também provocou divergências entre economistas. O Ministério da Fazenda justificou que o pagamento ao FMI ampliou a autonomia do Brasil na gestão de suas políticas macroeconômicas e maximizou sua confiança internacional, fortalecendo o mercado de capitais pátrio e diminuindo o risco-país. De acordo com o Ministério da Fazenda, essa decisão foi tomada com base:

[...] na melhora continuada das reservas internacionais ao longo dos últimos anos, no desempenho robusto das exportações, na melhora do perfil da dívida pública externa, cujo prazo médio das emissóes tem excedido 11 anos -, no ritmo do pré-financiamento da rolagem da dívida externa prevista para 2006, e na aquisição de divisas pelo Tesouro para o pagamento de juros e dívidas contratuais junto a organismos (Ministério da Fazenda 2010, 5).

Entretanto, diversos economistas e associações da sociedade civil defenderam que o governo brasileiro teria priorizado o pagamento de uma dívida que não precisava ser quitada naquele momento pelo simples fato de apresentar um taxa de juros bastante baixa ( $4 \%$ ao ano), como pode ser conferido no artigo de Carneiro (2010). Tal argumento se viu ainda mais reforçado quando foi lembrado que, no início de 2006, o governo antecipara novas captaçōes externas, no valor de US\$ 8 bilhões, pagando juros em torno de $8 \%$ a 12,75\% ao ano. Esses opositores ao pagamento antecipado ainda acrescentaram que a política econômica brasileira não havia se alterado em relação àquela que era defendida pelo FMI, reforçando a noção de que não havia necessidade econômica, naquele momento preciso, de realizar o pagamento.

Pode-se concluir desse debate que, para além dos argumentos econômicos, a decisão governamental foi claramente fundamentada na importância política desse pagamento antecipado ao FMI. No dia 16 de janeiro de 2006, o presidente Lula, em pronunciamento à nação em cadeia de rádio e TV, inicia o seu discurso com as seguintes afirmações:

Meus amigos e minhas amigas, há poucos dias o Brasil zerou a sua dívida com o FMI. Com isso, deixamos de pagar juros, e com essa economia vamos poder 
investir mais em favor do nosso povo. Com soberania viramos uma página da nossa história. O Brasil vai caminhar com suas próprias pernas. Ao devolvermos ao FMI o dinheiro que estava à disposição do Brasil por conta da crise de 2001-2002 estávamos provando, dentre outras coisas, que não dependemos mais de empréstimos externos para continuar crescendo, podemos fazê-lo com nossos próprios recursos [...] (Lula 2006).

O tema "pagamento antecipado do empréstimo ao FMI" se transformou em uma espécie de mantra repetido por Lula até o final do seu governo. Os temas "não renovação do acordo com o FMI", "pagamento antecipado ao FMI" e "não haver mais dívidas com o FMI" estiveram presentes em $95 \%$ dos discursos de Lula que citaram o FMI em 2005 e em 100\% no ano de 2006. Constata-se, assim, a elevada importância dada por Lula em expressar a desvinculação entre o governo federal com o FMI nesse período eleitoral. Foi justamente a partir da não renovação dos acordos com o Fundo que o Presidente Lula passou a aludir com maior frequência ao FMI nos seus discursos, como pode ser verificado na Tabela 1. Após a eleição de 2006, esses temas continuariam bastante frequentes nas falas de Lula sobre o FMI (em 2007 chegaram a 80\% e em 2008 a 60\%), mas passariam a ser menos pronunciados lentamente, sendo substituídos por outros que também ressaltavam a independência brasileira frente ao Fundo, como será visto adiante.

Observa-se nos discursos de Lula a existência de dois subtemas vinculados a esses temas que denotam a busca pela desvinculação entre o governo brasileiro e o FMI nas agendas externas, quais sejam: o "não rompimento com o FMI" e a "conquista de independência". Ao fazer uso de argumentos classificados no subtema "não rompimento com o FMI", o presidente Lula busca explicar que o processo de desvinculação com o FMI se deu sem conflitos ou rupturas. Já o subtema "Conquista de independência" é utilizado por Lula para afirmar que a não renovação dos acordos com o Fundo ou o fato de não dever mais para essa instituição traria como resultado maior independência e autonomia para o Brasil.

O subtema "não rompimento com o FMI" esteve presente em quase 45\% dos discursos de Lula (Figura 2) que abordam os temas da "não renovação do acordo com o FMI", do "pagamento antecipado ao FMI" e de "não haver mais dívidas com o FMI" em 2005. Entende-se que o governo Lula necessitava ressaltar aos investidores internacionais que essas decisões relativas ao FMI não significavam uma mudança nas políticas macroeconômicas brasileiras e nas relações com credores internacionais. À medida que a economia se consolidava, essas preocupaçôes se minimizavam, diminuindo a presença desse subtema nos discursos do presidente. 


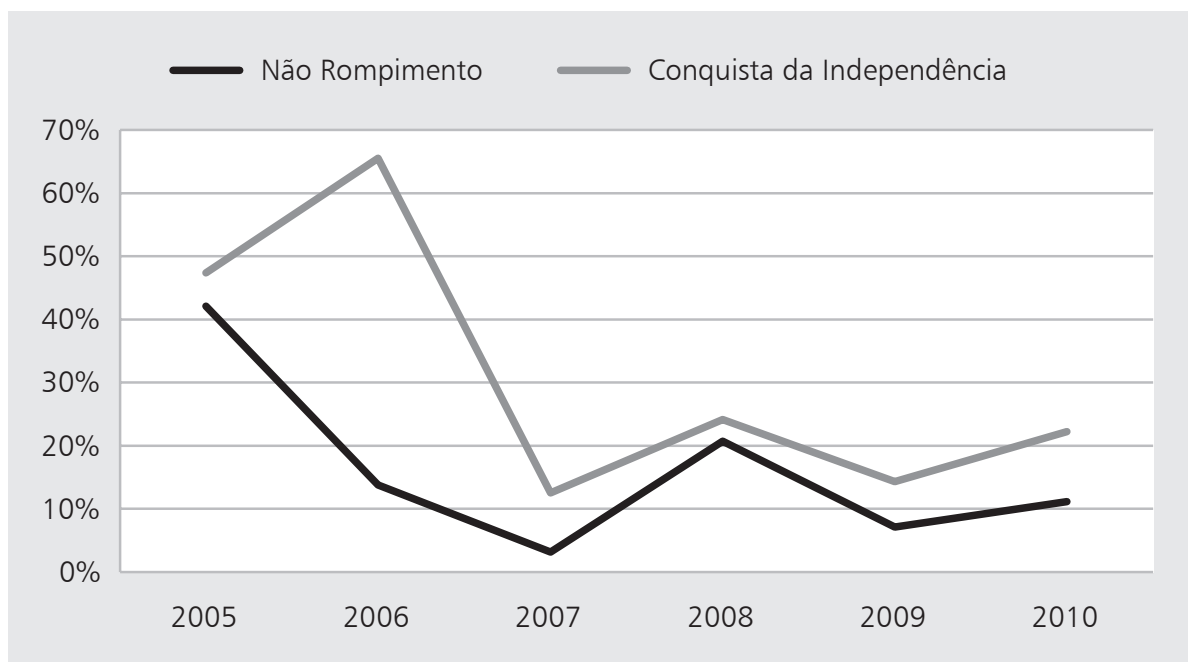

Figura 2. Frequências relativas dos subtemas "conquista da independência" e "não rompimento" nos discursos de Lula que abordam os temas da "não renovação do acordo com o FMI", do "pagamento antecipado ao FMI" e de "não haver mais dívidas com o FMI".

Fonte: elaboração própria.

Já o subtema "conquista da independência" esteve presente em quase 50\% dos discursos de Lula que abordam os temas da "não renovação do acordo com o FMI", do "pagamento antecipado ao FMI" e de "não haver mais dívidas com o FMI" em 2005, chegando a quase $70 \%$ em 2006, ano eleitoral, o que mostra a importância política dada às relações entre o Brasil e o Fundo pelo presidente então candidato a reeleição. A relação do Brasil com o FMI é tida pelo governo como a representação da "velha e crônica dependência econômica" do País que precisaria ser superada (Lula 2005). É relevante notar que, após o período eleitoral, esse subtema perdeu força nos discursos presidenciais e foi substituído por outros. Apesar desse esforço do presidente Lula em ressaltar o término da relação creditícia entre o Brasil e o Fundo, observa-se a inexistência de discursos que critiquem as políticas econômicas recessivas e o regime de condicionalidades do FMI até 2007, seja da parte do presidente, seja do lado de seus ministros da Fazenda e das Relações Exteriores.

No ano de 2006, no bojo das agendas da política externa brasileira de reforma da Organização das Nações Unidas (ONU), identificou-se outro posicionamento do governo federal em relação ao FMI. Foi o caso da defesa do aumento da interlocução dessa instituição com o Conselho Econômico e Social da ONU (Ecosoc). Entretanto, não se pode considerar tal posicionamento uma defesa de reforma propriamente dita do FMI, já que não propõe nenhuma alteração 
no seio da instituição, seja no seu modus operandi ou na distribuição de quotas entre os países. Sabe-se que o ministro Palocci defendia o aumento das quotas de participação brasileira no Fundo. Contudo, a única ocasião em que o presidente Lula defendeu uma reforma no FMI, propondo o aumento da participação brasileira, deu-se durante reunião com o então diretor-gerente do Fundo, Rodrigo de Rato, em janeiro de 2006.

Já em 17 de setembro de 2006, o ministro Guido Mantega discursou na Assembleia de Governadores do FMI, afirmando que "a gestão de crises havia sido a tônica da ação do FMI no século 20 e que a prevenção de crises deveria ser tomada como o principal objetivo para o século 21" (Mantega 2006). Assim, o ministro defendeu que o FMI deveria "completar o seu kit de ferramentas com um mecanismo de financiamento que visasse à prevenção de crises" (Mantega 2006). Nesse discurso, Mantega defendeu também a reforma do sistema de quotas e a distribuição dos votos na instituição, ampliando a participação dos países considerados sub-representados, argumentando que tal mudança seria fundamental para assegurar maior legitimidade para o Fundo. Essas posiçôes apresentadas pelos governantes brasileiros dialogam diretamente com alguns dos princípios constitutivos da política externa brasileira, a exemplo da defesa do multilateralismo, mas também são o reflexo das demandas brasileiras de democratização das instituições internacionais e de maior participação política de países em desenvolvimento no processo decisório dessas instituições. Entretanto, não emanou do governo, até fins de 2008, uma proposta de agenda de reformas do FMI, diferentemente do que ocorreu com as reformas do Conselho de Segurança da ONU e da Organização Mundial do Comércio (OMC).

Percebe-se que o FMI não se constituiu em uma prioridade na agenda de política externa do governo Lula, pelo menos até 2008, como se verá adiante. Predominou até 2008 a opiniáo de que a OMC e a ONU seriam organismos prioritários para a atuação brasileira no sistema internacional, visão esta que pôde ser confirmada a partir da aula magna de 2006, ministrada por Celso Amorim aos estudantes do Instituto Rio Branco:

É que eu volto aqui ao roteiro do Eugênio e eu li lá, o Eugênio tinha feito no seu roteiro, depois vocês vão ler, as duas organizações mais importantes do sistema multilateral são a $\mathrm{ONU}$ e $\mathrm{OMC}$. E eu em um primeiro momento tive até uma dúvida - e olha que eu trabalhei duas vezes embaixador da $\mathrm{OMC}$-, eu falei "Será que eu posso dizer isso?" Digamos, colocando de lado, em segundo plano, o Banco Mundial e FMI, mas eu acho que a avaliação do Eugênio está certa, porque no fundo são mesmo os dois organismos mais importantes.

Não é que o Banco Mundial não tenha funções importantes, o FMI não tenha funções importantes. Mas, para começar, o processo decisório nesses órgãos é totalmente concentrado, eles desempenham funçóes importantes para o sistema multilateral, mas realmente eles não estão no centro do sistema multilateral como processo de decisão. E eu diria também, em um sentido mais profundo 
que, também do ponto de vista, onde está a verdadeira solução para os países pobres, eu acho que ela está dos dois lados, mas ela está mais na OMC que no Banco Mundial e no FMI. No FMI nem falar, mais do que no Banco Mundial. Porque através de um comércio mais justo, mais aberto, que reconheça também as assimetrias e as necessidades de tempos para a adaptação que os países em desenvolvimento podem realmente realizar as condiçôes para seu crescimento econômico, para sua justiça social. (Amorim 2006).

Diante do exposto até então, verifica-se que, no primeiro mandato de Lula, a política externa em relação ao FMI foi regida por uma dupla lógica. Uma primeira de caráter político-doméstico, que buscou atender aos anseios de setores do PT e de camadas da população do País que interpretam as relações com o Fundo sob a chave da subordinação política e do anacronismo econômico. Assim, o presidente procurou, de maneira reiterada, expressar a não existência de vínculos de dependência, mas tampouco de conflitos, entre o seu governo e o FMI, especialmente em período eleitoral. Uma segunda lógica concomitante foi mais voltada para o cenário externo, quando o governo manteve uma racionalidade pragmática em relação ao Fundo, utilizando-se de seus serviços creditícios quando necessário, não criticando diretamente suas políticas, nem confrontando seus interesses, ao mesmo tempo em que ressaltava seu respeito a essa instituição financeira. Essa segunda lógica, a racionalidade pragmática, buscou a manutenção da confiança junto ao mercado internacional, esperando que, com isso, fosse possível assegurar uma imagem de estabilidade econômica e notaçôes mais elevadas para o Brasil junto às agências internacionais de rating.

Além disso, percebe-se que, apesar das diversas ações diplomáticas no sentido de estimular a alta gerência do FMI a desenvolver mecanismos alternativos de financiamento à pobreza e ao desenvolvimento, de defender sua aproximação com o Ecosoc, de estabelecer novas formas de cálculo do superávit dos países em desenvolvimento, ou mesmo no sentido de reconfigurar as relações de poder no plano regional sul-americano por meio do apoio à criação e ao desenvolvimento do Banco do Sul, o governo Lula não manteve uma agenda de política externa ativamente orientada para o debate de propostas sobre as reformas institucionais mais substantivas da arquitetura financeira internacional.

\section{Uma nova agenda para a política externa brasileira em relação ao $\mathrm{FMI}$}

No início de 2007, a política do governo Lula para com o FMI não se alterou profundamente, havendo uma continuidade em relação ao primeiro mandato. Nesse ano, o presidente Lula mencionou o FMI em 11,4\% dos seus discursos, e $74 \%$ deles abordaram os temas "não renovação do acordo com o FMI", "pagamento antecipado ao FMI" e "não haver mais dívidas com o FMI". Já o embaixador 
Celso Amorim, nesse ano, somente se referiu ao Fundo uma única vez em seus pronunciamentos publicados no site do MRE, momento em que voltou a defender a aproximação dessa instituição com o Ecosoc.

Entretanto, observa-se que a crise mundial que se iniciou nos EUA em meados de 2007 modificou a política do governo brasileiro para com o FMI. A partir do final desse ano, Lula passou a ressaltar a relação de independência financeira do Brasil diante do Fundo mesmo em tempos de crise econômica, assim como passou a enunciar críticas contundentes às políticas econômicas de austeridade e às condicionalidades do FMI. Outro tema sobre o FMI que foi muito pronunciado pelos dirigentes do governo Lula, a partir de 2009, foi a ineficiência do Fundo diante da crise que se iniciou nos Estados Unidos.

O grande efeito que a crise mundial iniciada em 2007 produziu nas agendas da política externa foi a mudança de prioridade em favor das reformas institucionais do FMI. Como afirma o MRE, "o Brasil percebeu, durante a crise financeira, o surgimento de uma oportunidade para a mudança na estrutura do sistema financeiro e econômico internacional" (MRE 2010). Como estratégia de mobilização política para a realização das reformas defendidas, o governo brasileiro passou, ademais, a empenhar esforços diplomáticos principalmente em duas instâncias distintas: no G-20 financeiro e no âmbito do grupo Brasil, Rússia, Índia e China (Bric). No âmbito do G-20 financeiro, o governo passou a apoiar "vigorosamente os trabalhos do grupo e atuou como um dos principais atores no processo de consolidação do G-20 como principal foro para lidar com temas econômicos internacionais" (MRE 2010). Já no âmbito do Bric, o País vem articulando ações políticas no sentido de pressionar o FMI em favor das reformas institucionais consideradas relevantes na perspectiva desses países. Algumas dessas ações contribuíram para que um novo acordo sobre créditos e empréstimos entrasse em vigor em 2011, os chamados "New Arrangements to Borrow" (NAB), na terminologia do Fundo.

A partir de 2008, especialmente após as primeiras reunióes do G-20 financeiro e do Bric, o tema "reforma do FMI" passou a aparecer com elevada frequência nas agendas e discursos do presidente Lula e do ministro Celso Amorim, não ficando mais restrito ao Ministério da Fazenda. É verdade que esse tema foi menos pronunciado em 2010, o que poderia ser explicado pela necessidade de apresentar propostas mais moderadas em ano eleitoral e pela mudança de liderança no governo que ocorreria de todas as formas, seja com José Serra, seja com Dilma Rousseff. Antes disso, até 2009, o governo brasileiro passou a defender reformas significativas do Fundo e passou a se colocar enfaticamente contrário a qualquer reforma minimalista, "que simplesmente mexa nas margens", argumentando que isso:

[...] poria em questionamento a relevância e a legitimidade do Fundo. Os países em desenvolvimento, ou muitos deles, acabariam por seguir seu próprio caminho, caso se tenha a percepção de que essas reformas não ocorrerão ou que elas sejam meramente cosméticas. Procuraremos auto-segurança construindo 
altos níveis de reservas internacionais e participando de instituições monetárias regionais. A fragmentação do sistema multilateral, que já está surgindo, vai se acelerar (Mantega 2007).

Nesse momento, o principal "porta-voz" das mudanças defendidas pelo governo Lula para o Fundo é o ministro Mantega, representante oficial do Brasil junto ao FMI. Os pontos principais dessas reformas - que desde então vêm sendo defendidas - são os seguintes:

1. Nova fórmula para alocar as cotas de participação dos países sócios do Fundo, distribuindo maior quantidade de cotas aos países em desenvolvimento.

2. Revisão das cotas periodicamente a cada cinco anos, para que reflitam a posição relativa dos países membros na economia mundial.

3. Criação de um novo instrumento de liquidez concebido, especificamente para apoiar os esforços de prevenção a crises;

4. Revisão da maneira de seleção do diretor-geral e do diretor-geral adjunto, adotando um processo aberto, transparente e baseado no mérito, sem levar em conta a nacionalidade.

5. Reforma dos instrumentos e condiçôes de empréstimos, minimizando as condicionalidades excessivas e intrusivas.

6. Aumento de recursos do fundo.

7. Maximizar a vigilância sob as economias desenvolvidas.

Essa priorização dada às reformas do FMI passou a orientar as ações do governo de Lula para com o Fundo, buscando maximizar a influência brasileira nessa instituição. Na reunião do G-20 de 2009, em Londres, os países com recursos disponíveis decidiram fazer aportes de modo que o FMI arrecadasse US\$ 500 bilhões. Dessa forma, em abril de 2009, o ministro Guido Mantega anunciou um acordo com o FMI para participar do Plano de Transações Financeiras (PTF), fato que concedeu ao Brasil posição de credor do FMI. Na época, 47 dos 185 membros do Fundo integravam o PTF.

Além da quota de US\$ 4,5 bilhóes, Mantega afirmou que "a entrada no chamado plano de transações financeiras do FMI não anula a decisão do Brasil de fazer um aporte adicional ao organismo, como parte de um esforço internacional para elevar a capacidade de financiamento do fundo" (Versiani e Costa 2009). O valor de tal aporte fora pensado, inicialmente, em US\$ 10 bilhões, mas, em novembro de 2009, o Ministério da Fazenda anunciou que, em uma ação articulada com os demais membros do Bric, a sua contribuição ao FMI subiria para US\$ 14 bilhões, podendo o Brasil, dessa forma, integrar-se aos Novos Acordos de Empréstimos, tradução para o termo NAB já mencionado. De acordo com nota divulgada pelo Ministério da Fazenda: 
A reunião de ontem concluiu uma etapa decisiva de um processo de negociação iniciado há cerca de 9 meses. Nesse processo, o Brasil atuou em estreita cooperação com os demais integrantes dos BRICs (Rússia, Índia e China). O resultado dessa cooperação foi uma vitória política importante, de caráter inédito. Pela primeira vez na história do FMI, os quatro países em conjunto terão efetiva capacidade de veto na instituição. No novo NAB, somente os BRICs, os Estados Unidos, o Japão e o conjunto dos países da União Européia terão poder de veto sobre as principais decisões. [...] O Brasil vinha buscando três objetivos na negociação do NAB. Primeiro, que o NAB tivesse caráter temporário, servindo de ponte para a reforma de quotas, que deve ser concluída até janeiro de 2011 e permitirá reequilibrar o poder decisório no FMI em favor dos países em desenvolvimento. Segundo, que o aporte de recursos ao NAB pudesse ser feito mediante a aquisição de notas ou bônus. Terceiro, que o Brasil, conjuntamente com os outros BRICs, tivesse influência real sobre a reforma do NAB, a sua governança e especificamente sobre como esse vasto volume de reservas será utilizado. Os três objetivos foram alcançados. Quanto ao primeiro, decidiu-se que o novo NAB vigorará até novembro de 2012 . Uma nova negociação das regras do NAB deverá ocorrer até novembro de 2011. Nessa data, o Brasil já saberá os resultados da reforma de quotas (em termos de redistribuição de quotas e votos entre os países membros e, também, de aumento no valor total das quotas do FMI). À luz disso, poderá decidir se mantém ou não a sua participação no financiamento do Fundo. Se o resultado da reforma de quotas for satisfatório, o Brasil poderá manter uma participação no NAB ou, ainda, converter a sua contribuição ao NAB em aumento da sua quota no FMI. Caso contrário, o Brasil poderá decidir encerrar a sua participação no NAB. Quanto ao segundo objetivo, decidiu-se que os participantes poderão optar entre contribuir por meio de empréstimos ou pela aquisição de notas emitidas no âmbito do NAB. Quanto ao terceiro, ficou estabelecido que os BRICs passarão a deter em conjunto mais de $15 \%$ de participação no acordo. Este percentual lhes dá poder de veto sobre as principais decisões que serão tomadas pelo NAB (Ministério da Fazenda 2009b).

Essa nota evidenciou a estratégia brasileira, em conjunto com os demais membros do Bric, de pressionar o Fundo por reformas do sistema de quotas. Esse empréstimo ao Fundo passou a ser um tema muito pronunciado pelo presidente Lula, estando presente em cerca de 45\% do seus discursos sobre o FMI em 2009 e em $60 \%$ em 2010.

A título de síntese, verifica-se que a política do governo Lula em relação ao FMI foi de pequenos ajustes no início do seu segundo mandato, não tendo produzido mudanças significativas em relação ao primeiro mandato. Contudo, com o recrudescimento da crise iniciada nos Estados Unidos, a política externa sofreu mudança mais profunda, enfatizando a demanda por transformação institucional do FMI. Dessa forma, primeiramente se observou uma diversificação de temas relativos ao FMI nas agendas e pronunciamentos dos dirigentes brasileiros, 
podendo-se constatar o surgimento de críticas mais contundentes sobre a atuação do Fundo, principalmente no que diz respeito a suas políticas econômicas prescritas, às condicionalidades e à apatia regulatória da instituição diante da crise financeira sistêmica. Verifica-se, ademais, que a reivindicação de reformas no FMI se fortaleceu no segundo mandato de Lula, englobando não mais exclusivamente o Ministério da Fazenda, mas também o Ministério das Relações Exteriores e a própria Presidência. Definitivamente a partir de 2008, a defesa de reformas para o FMI entrou na agenda prioritária da política externa brasileira. Como estratégia de pressão por tais reformas, o governo passou a se articular com os demais membros do Bric, cada vez mais presentes nas diferentes agendas da política externa brasileira (comércio, modelos de desenvolvimento, cooperação técnica e científica, segurança internacional, etc.).

Entretanto, ponto que nos parece fundamental, essa mudança de postura frente ao FMI não significou que Lula tenha mudado seu discurso para o público doméstico. Nessa segunda fase ainda persistia nos discursos do presidente a preocupação em ressaltar para a população brasileira a não subserviência do Brasil ao Fundo. De fato, ao longo de todo o segundo mandato, a mensagem passada repetidamente à população brasileira era de que o FMI não mais exerceria controle político sobre o Brasil, mas sim o Brasil passaria a exercer maior influência nas dinâmicas institucionais e financeiras do Fundo.

\section{Considerações finais}

Este artigo teve por objetivo compreender as principais características da política externa do governo Lula em relação ao FMI e seus processos de reformas, utilizando-se dos métodos de pesquisa bibliográfica e análise de conteúdo de pronunciamentos oficiais (Bardin 1977). A primeira constatação a que chegamos é a existência de duas dimensões distintas dessa política, bem delimitadas, mas que se influenciam mutuamente: a dimensão doméstica da política externa brasileira e a sua dimensão sistêmica (Lima 2000; Hirst e Pinheiro 1995). Na sua dimensão doméstica, verifica-se que a política externa em relação ao Fundo se pautou na ênfase à independência e à autonomia do Estado nacional. Os temas mais pronunciados pelo presidente Lula sobre o Fundo em seus discursos buscavam transmitir a ideia de não subserviência do Brasil em relação a essa instituição e de transformação histórica das relações políticas e institucionais do País com o FMI. O ideal da inserção internacional soberana do Brasil está nas bases desse posicionamento do governo Lula.

No entanto, considerando que o FMI é um objeto político bastante controverso - principalmente pela sua liderança, entre os anos 1980 e 1990, na condução da agenda de ajuste macroeconômico em países em desenvolvimento e que sua imagem pública no Brasil é alvo de vários ataques, da esquerda e das correntes nacionalistas, pode-se levantar a hipótese de que o presidente Lula tenha 
utilizado a relação com o Fundo de maneira político-eleitoral, outro aspecto da dimensão doméstica da política externa brasileira com o FMI. É evidente que não se deve entender que o plano doméstico subordine a dimensão sistêmica, mas sim pensar ambas as dimensões dialeticamente, em tensão e contradição constantes ao longo dos dois mandatos do presidente Lula. Entre 2003 e 2010, a política externa com o FMI mostrou-se pragmática, foi orientada pelos princípios orientadores das políticas macroeconômicas e, ao mesmo tempo, procurou aproximar-se das bandeiras de luta mais tradicionais do Partido dos Trabalhadores, mormente a partir do segundo semestre de 2007.

De fato, em sua dimensão sistêmica, a política externa do governo Lula para com o Fundo pode ser dividida em dois momentos: do início do governo a meados de 2007, a fase da não confrontação; da crise estadunidense até o final do governo, a fase de priorização das demandas por reformas institucionais. Na sua primeira fase, a política externa buscou respeitar acordos e evitar confrontações com o FMI, objetivando, com isso, evitar quaisquer empecilhos para o reestabelecimento da confiança internacional na economia do País. Nessa primeira fase, o FMI não foi prioridade na agenda de política externa brasileira, e as reformas institucionais foram defendidas apenas pelos ministros da Fazenda, mas de maneira pouco enfática e desarticulada da política externa. Ou seja, tudo indica que parecia inexistir, ainda nesse momento, um projeto político consolidado no seio do governo a fim de definir a sua relação com o FMI, ou então que, do ponto de vista sistêmico e da estabilidade macroeconômica do País, o momento ainda não fosse condizente com mudanças mais profundas nas relações institucionais com o FMI.

Entretanto, a partir da crise de 2007 - e após haver reconquistado confiança internacional e acumulado elevadas reservas internacionais -, o governo passou a tecer críticas contundentes ao Fundo, especialmente às suas políticas econômicas liberais e sua ineficácia diante da crise. Essas críticas foram igualmente acolhidas por outras reivindicações oriundas de economias emergentes e potências intermediárias no cenário internacional, a exemplo da África do Sul, da Índia e da Turquia. Em seguida, e a partir das articulações em torno do G-20 financeiro e do grupo Bric, o governo passou a priorizar o tema da reforma do FMI, articulando, na política burocrática, os interesses da Presidência da República e dos ministérios da Fazenda e das Relaçôes Exteriores. Nesse momento, havia no governo a crença de que a crise constituiria momento singular em termos de mudança potencial no sistema financeiro internacional, devendo o Brasil buscar maximizar a projeção de seus interesses estratégicos. Observa-se que tal posição se encontrava em congruência com as diretrizes da política externa brasileira, no sentido da defesa do multilateralismo, da prioridade à cooperação Sul-Sul, bem como de maior autonomia e participação dos países em desenvolvimento no sistema econômico e político internacional (Vigevani e Cepaluni 2011).

A partir dessa busca por reformas, o Brasil estabeleceu sua política em relação ao FMI, guiando suas ações no sentido de assegurar sua presença no debate sobre 
a governança da instituição, por exemplo, ao decidir conceder US\$ 14 bilhões ao FMI a fim de obter, conjuntamente com os demais membros do Bric, aumento de seu poder de voto. Corroborando a ideia de que a política externa com o FMI não se subordinou à política doméstica, mas que ambas se reforçaram mutuamente, o fato de o Brasil ter se tornado credor do Fundo foi amplamente utilizado por Lula para apontar novos tempos nas relaçóes do Brasil com as agências financeiras internacionais, além de sinalizar política e publicamente para o contraste entre esse perfil por ele apresentado como mais altivo e soberano e o momento dos dois mandatos de Fernando Henrique Cardoso. As relaçôes do Brasil com o FMI eram, nesse sentido, instrumentalizadas a fim de tentar diferenciar padrões de comportamento político do Estado nacional na ordem econômica internacional.

De fato, esse uso político da relação entre dimensões externa e doméstica é uma característica peculiar da política externa do governo Lula, uma vez que se observa, com elevada frequência nos discursos do presidente, uma conciliação retórica estratégica entre ataques e afagos ao FMI e suas políticas. Sem dúvida, trata-se também de um elemento da idiossincrasia de um presidente sindicalista, cuja cultura política lhe permitia lidar diretamente com o conflito dentro da dinâmica de governo e, ademais, habilidade de conciliação e negociação nos planos doméstico e internacional. É evidente que, a partir das pesquisas cujos resultados foram aqui apresentados, ficam em aberto algumas questôes, a serem exploradas em futuros projetos, inter alia: qual a influência que a política externa brasileira vem exercendo nos processos de reformas em curso no FMI desde 2008? De que forma o Brasil constrói sua política de demanda por reformas no FMI em parceria com os demais membros do Bric? Como se dá a participação brasileira no âmbito do G-20? Como a busca por reformas do FMI vem sendo tratada pelo Brasil no plano regional sul-americano?

\section{Referências bibliográficas}

ALMEIDA, Paulo Roberto de (2004). O Brasil e a Construção da Ordem Econômica Internacional Contemporânea. Contexto Internacional, Rio de Janeiro, v. 26, N. 1, 2004. p. 7-63.

AMORIM, Celso (2006). Aula Magna do Ministro das Relaçóes Exteriores aos Alunos do Instituto Rio Branco. Brasília.

BARDIN, Laurence (1977). Análise de conteúdo. Lisboa: Edições 70.

CARNEIRO, Maria Lucia Fattorelli (2010). Contradição Inexplicável: Por que o Governo Lula acelera endividamento caro e quita antecipadamente dívida bem mais barata?, publicado em: [http://www.cecac.org.br/MATERIAS/FMI_farsa_do_pagamento.htm]. Disponibilidade em: 10 nov. 2010.

CERVO, Amado Luiz; BUENO, Clodoaldo (2010). História da política exterior do Brasil. Brasília: Ed. UNB. 
FONSECA JR., Gelson (1998). A Legitimidade e outras questóes internacionais: poder e ética entre as nações. São Paulo: Paz e Terra.

GONÇALVES, Reinaldo (2005). Economia Política Internacional. Rio de Janeiro, Ed. Elsevier.

FOLHA DE SÃO PAULO (2004). Sinais trocados: projeto do FMI pode não aliviar restrição fiscal. Folha de São Paulo, São Paulo, p. B1. 28 abr. 2004.

HIRST, Monica. Brasil - Estados Unidos: desencontros e afinidades (2009). Rio de Janeiro: FGV de Bolso.

HIRST, Monica; PINHEIRO, Leticia. A Política Externa Brasileira em dois tempos (1995). Revista Brasileira de Política Internacional, vol. 38, n. 1, p. 5-23.

LIMA. Maria Regina Soares de. Instituições Democráticas e Política Exterior (2000). Contexto Internacional, vol. 22, n. 2, p. 265-303.

LULA da Silva, Luiz Inácio (2003a). Discurso do Presidente da República em visita ao Retiro de Itaici - CNBB Indaiatuba. São Paulo, $1^{\circ}$ de maio de 2003.

LULA da Silva, Luiz Inácio (2003b). Discurso do residente da República na cerimônia de inauguração da nova fábrica da Pirelli. Feira de Santana-BA, 12 de setembro de 2003.

LULA da Silva, Luiz Inácio (2003c). Discurso do Presidente da República no Conselho de Relaçóes Internacionais - Council on Foreign Relations. Nova Iorque (EUA), 25 de setembro de 2003.

LULA da Silva, Luiz Inácio (2005). Pronunciamento à nação do Presidente da República em cadeia de rádio e tv por ocasiáo do Dia do Trabalhador. $1^{\circ}$ de Maio, 30 de abril, 2005.

LULA da Silva, Luiz Inácio (2006). Pronunciamento à nação do Presidente da República em cadeia de rádio e TV, sobre o pagamento da dívida com o FMI. Brasília, 16 de janeiro de 2006.

MANTEGA, Guido (2006). Discurso proferido pelo Ministro da Fazenda do Brasil no International Monetary and Financial Committee (IMFC). Washington, 17 de setembro de 2006.

MANTEGA, Guido (2007). Discurso proferido pelo Ministro da Fazenda do Brasil no International Monetary and Financial Committee (IMFC). Washington, 20 de outubro de 2007.

MINISTÉRIO DAS RELAÇÕES EXTERIORES (2010). G-20 Financeiro, publicado em: <http://www.itamaraty.gov.br/temas/temas-multilaterais/governanca-global/g-20-financeiro >. Disponibilidade em: 5 ago. 2010.

MINISTÉRIO DA FAZENDA DO BRASIL (2009). Brasil passa a integrar a lista de credores potenciais do FMI, publicado em: <http://www.fazenda.gov.br/audio/2009/abril/a090409. asp>. publicado em: 9 abr. 2009.

MINISTÉRIO DA FAZENDA DO BRASIL (2010). O pré-pagamento do emprétimo do Brasil junto ao Fundo Monetário Internacional, publicado em: <http://www.fazenda.gov. br/portugues/releases/2005/r131205.asp>. Disponível em: 5 jul. 2010.

VALOR ECONÔMICO, São Paulo, 23 fev. 2005. 
VERSIANI, Isabel; COSTA, Ana Nicolaci da (2009). Brasil integrará grupo de credores do FMI, publicado em: <http://br.reuters.com/article/topNews/idBRSPE5380KX20090409>. Disponível em: 9 abr. 2009.

VIGEVANI, T.; OLIVEIRA, M.; CINTRA, R (2003). Política externa no período FHC: a busca de autonomia pela integração. Tempo Social, vol. 15, n. 2.

VIGEVANI, Tullo; CEPALUNI, Gabriel (2011). A política externa brasileira: a busca da autonomia, de Sarney a Lula. São Paulo: Editora UNESP.

Recebido em 2 de dezembro de 2012

Aprovado em 5 de fevereiro de 2013

\section{Resumo}

Este artigo tem como objetivo analisar a política externa do governo Lula em relação ao Fundo Monetário Internacional (FMI). Por meio de pesquisa bibliográfica e documental dos pronunciamentos oficiais do presidente, do chanceler e dos ministros das finanças entre 2003 e 2010, os autores articulam as dimensões doméstica e sistêmica desse campo da política externa, discutindo as estratégias adotadas pelo governo na relação com o FMI.

Palavras-chave: Fundo Monetário Internacional; governo Lula; organizações internacionais; Política Externa Brasileira.

\section{Abstract}

This article aims to discuss Brazil's foreign policy towards the International Monetary Fund (IMF), highlighting its domestic and systemic dimensions, through bibliographical research and an analysis of the official statements made by the president, the chancellor and treasurers between 2003 and 2010.

Keywords: International Monetary Fund; Lula Administration; international organizations; Brazilian Foreign Policy.

\section{ERRATA}

Errata do artigo "A Política Externa Brasileira em relação ao Fundo Monetário Internacional durante 0 Governo Lula" (http://www.scielo.br/pdf/rbpi/v56n1/05.pdf)

\section{Onde se lê:}

Carlos Sanchez Milani é professor adjunto da Universidade Federal do Rio de Janeiro (UFRJ)

\section{Leia-se:}

Carlos R. S. Milani é professor adjunto do Instituto de Estudos Sociais e Políticos da Universidade do Estado do Rio de Janeiro (IESP-UERJ) 